\title{
Cambio y continuidad: el Pacto Andino en la historia contemporánea
}

\begin{abstract}
CLAudro VÉLIZ, Director del Instituto de Estudios Internacionales de la Universidad de Chile desde su fundación, en 1966, posee el grado de Ph. D. (Historia económica) de la Universiclad de Londres. Es miembro de la Royal Historical Society y entre sus obras se cuentan, Historia de la Marina Mercanle de Chile, Santiago, 1961, (Ed.) Obstacles to Change in Latin America, Oxford University Press, 1965, (Ed.), The Politics of Conformity in Latin America, Oxford University Press, 1967. Durante el período 1962-1966, ocupó el cargo de Senior Research Fellow en el Royal Institute of International Affairs, de Londres. Actualmente ocupa además la cítedra de Política Internacional en la Academia de Guerra de Chile.
\end{abstract}

Entre las tareas con que necesariamente debe enfrentarse el estudioso de los asuntos contemporáneos, está la de discernir de la inmensa masa de información y datos clisponibles, los factores políticos y culturales de cambio $y$ continuidad $y$ su importancia relativa. Desde cierto punto de vista, pareciera que cambios $y^{\prime}$ continuidades fueran reemplazándose, superponiéndose, apoyánclose y alterándose en un devenir confuso y difícilmente susceptible de ser analizado sin el auxilio de una visión perspectiva. Sin embargo la perspectiva del tiempo ni resuelve el problema, ni tampoco lo hace necesariamente más fácil. Son numerosísimos los casos históricos de factores que han sido mirados con incliferencia durante siglos para adquirir luego una importancia singular a la luz cle circunstancias cambiantes que hubiera sido muy difícil si no imposible anticipar. He ahi el caso del Shintoismo en el Japón; eclipsado clurante el largo período en que el pais estuvo gobernado por el shogun Tokugawa, empezó a recobrar su importancia hacia fines del siglo dieciocho para luego vertebrar en forma significativa los esfuerzos exitosos realizados durante la restauración Meiji para inclustrializar y hacer militarmente fuerte a esa nación. Es difícil imaginar que un erudito japonés de fines del siglo xi'I hubiera podido pensar que el Shintoísmo - tan enfáticamente tradicionalista - llegaría a jugar un papel importante precisamente en la modernización e inclustrialización del país. 
Igualmente inconcebible hubiera sido que - por ejemplo- un observador francés del siglo xur hubiera podido descubrir $y$ analizar cleritro de la vida cultural contemporánea aquellas continuidades y factores de cambio que a poco andar harían de la antiguiedad grecoromana motivo principal de interés e inspiración para toda Europa. ¿Quién podría suponer que un historiador inglés, testigo presencial de la ejecución de Carlos I por el régimen puritano cle Cromwell, imaginaría que trescientos años más tarcle Gran Bretaña continuaría siendo una monarquía? Por el contrario, cuán difícil hubiera sido apreciar, el día en que Francia recibió la noticia de la muerte de Napoleón, que aquella gran nación sería tan entusiastamente republicana a la vuelta de pocas décadas?

Todo esto aparece complicaclísimo si se mira a posteriori y' se atribuye a aquellos lejanos historiaclores una intención profética, pero situándonos en el presente y' eliminando cualquier afán por auscultar el futuro, enfrentarse con este problema con una actitud científica continúa sienclo de la esencia misma del quehacer histórico contemporáneo.

Valga este preámbulo para explicar el porqué he escogido este tema cliscutible $y$ aparentemente vago como digno de reflexión $y^{\prime}$ estudio: estimo importante dedicar tiempo y esfuerzo a tratar de determinar cuáles son los factores de cambio $y$ continuidad que modifican, encauzan, atenúan o dinamizan la actividad política y econó. mica de los países que firmaron el Acuerdo de Cartagena.

\section{LAS CONTINUUIDADES}

Inevitablemente se corre el riesgo de simplificar al seleccionar sólo algunos aspectos de una rica experiencia histórica para apoyar una hipótesis de trabajo, sin embargo, consciente de este riesgo, me gustaria sugerir que existen en nuestra situación contemporánea tres factores que me atrevería a clasificar como continuidades relativas en nuestro desarrollo histórico $y^{\prime}$ que - según explicaré más adelantepodrían adquirir en estos momentos una importancia muy grande al reforzar $y$ dinamizar ciertos factores cle cambio que de otro modo tendrían un efecto más atenuado.

\section{EL CENTRALISMO POLITICO}

Primeramente, América Latina en general, y los países del Pacto Andino en particular poseen una compleja tradición centralista que ha 
sobrevivido vicisitudes, desafíos $\mathrm{y}^{\prime}$ modificaciones institucionales $\mathrm{y}$ que hoy día se vislumbra como uno de los factores que afectan con igual intensidacl a países tan disímiles como México y Chile; Cuba y Argentina; Perú y Colombia. He examinaclo esta proposición en algún detalle anteriormente $y^{\prime}$ sólo me referiré a ella brevemente ${ }^{1}$.

Estimo que la traclición centralista de América Latina se maniliesta significativamente en la vicla política, religiosa y' económica de nuestras naciones clescle su creación moderna, en el siglo xvi, hasta nuestros dias, en que ha evolucionado hasta transformarse en un fenómeno sui generis que con alguna trepidación podríamos denominar "populismo centralista".

Esta tradición centralista nuestra difiere fundamentalmente de aquella que informa los moclelos principales de interpretación políLica y económica provenientes del ámbito noratlántico y que han sido utilizados en América Latina durante las últimas clécadas - sin mucho éxito- como pautas para la acción. Creo que estos modelos incluyen clescle luego a cinco corrientes políticas troncales que han dominaclo nuestra vicla pública clurante el último siglo -el radicalismo, el liberalismo, el conservantismo, el socialismo y la democracia cristiana- $y$ cualesquiera las variaciones que les ha impreso la vivencia latinoamericana, todos tienen un origen común en la interpretación crítica y clinámica que los europeos dieron a los fenómenos que acompañaron a la Revolución Industrial en ese continente durante el siglo $x I x$.

Todos estos modelos participan cle una tradición política pluralista, en el sentidlo que incluye el concepto dinámico de un poder comparticlo entre un centro y una periferia de grupos de presión relativamente fuertes clescle los cuales provienen frecuentemente iniciativas que pueden modificar substancialmente la estructura institucional y' la modalidad cle conducción de los asuntos públicos. La tradición histórica de América Latina, por el contrario, excluye, en general, el concepto del poder comparticlo y se ciñe a un cauce centralista clefinido clesde sus mismos orígenes.

Tres omisiones importantes pueden ser seleccionadas para ilustrar esta experiencia histórica. En primer lugar, América Latina nunca pasó por la etapa feudal que de modo tan decisivo modificó las instituciones políticas y sociales de Europa. América Latina fue prácticamente creada a principios del siglo Xvi - por lo menos tres siglos

'Claudio. Véliz, Centralism and Nationalism in Latin America, Foreign dffairs, October, 1968; Ccntralismo, nacionalismo e integración, Estudios Intemacionales, abril-junio, . 1969. 
después de que el feudalismo había desaparecido como factor principal en la vida política de Europa - por la monarquía centralista más fuerte de la cristiandad ${ }^{2}$.

Muerta Isabel la Católica, el rey Fernando de Aragón retuvo en sus manos el poder temporal absoluto no sólo dentro de sus territorios ibéricos, sino que también en las Indias recién conquistadas. Los pequeños brotes de disidencia aristocrática y regionalista dentro de España fueron eliminaclos rápida $y$ brutalmente $y$ la monarquía central gobernó sin rivalidades ni oposición dignas de ser mencionadas. Pero además, a raíz de la bula Universalis ecclesiae regimini otorgada por el Papa Julio II en 1508, el monarca español obturo un poder casi absoluto en materias eclesiásticas sobre los territorios del Nuevo Mundo". Una generación antes de que Enrique vin de Inglaterra desafiara al Papa en si intento por obtener poderes similares, Fernanclo de Aragón podía vanagloriarse con razón de ser el monarca más fuerte del munclo cristiano, tanto por su hegemonía temporal como por su poder eclesiástico. Fue este monarca asesorado por ministros tanto y más centralistas que él, quien delineó la gran estructura administrativa y política que clurante trescientos años canalizó la vicla pública de América Latina. El imperio español fue el más centralizado de la época moderna $y$ esa experiencia histórica dejó marcas profundas en la institucionaliclad política latinoamericanat.

"La limitación del poder de la nobleza castcllana fue uno de los aspectos importantes de la política doméstica de Isabel la Católica. Desde luego las disposiciones financieras que emergieron de las Cortes de Toledo de 1480 y que con tanta austeridad $y$ cficiencia fucran llevadas a la práctica por el confesor de la reina, Fernando de Talavera, redujeron significativamente el poder financiero de los nobles. Lucgo la prohibición de que construyeran plazas fuertes y la creación de la Santa Fermandad, un cuerpo armado leal a la corona central, limitaron considelablemente su poderío militar. Además, otras disposiciones como la prohibición de batirse a duelo $y$ de adoptar "un estilo real" en sus modales sociales o manera cic vestir, contribuyeron a indicar a la nobleza que la monarquía no estaba dispuesta a compartir ni siquiera la apariencia dicl poder con la periferia. Sobre esto, rè el clásico estudio de William H. Prescott, History of the Reign of Ferdinand and Isabella the Catholic, London, 1885, p. I46 et seqq; ver también el sugerente estudio de Luis Vitale, España antes y después de la conquista de América, Pensamiento Critico, La Habana, Cuba, abril, 1969.

- "John H. Parry, The Spanish Seaborne Empire, London, 1966, pp. 154-155.

${ }^{4} L a$ fuerte tradición legalista que caracteriza la) vida pública de nuestra América Latina corre paralela con el centralismo autoritario impuesto desde Madrid por Fernando de Aragón. Vale la pena recordar que uno de los factores principales en la unificación de la península fue el desarrollo gradual de un sistema jurídico centralizado que desde el Fuero Juzgo, pasando por las Siete Partidas hasta la Nucva Recopilación de Leyes de España de 1576, fue incorporando y sistematizan- 
La característica política fundamental del feudalismo no es, como lo suponen algunos, el maltrato de los campesinos o subordinados, sino una distribución del poder político efectivo entre un centro relativamente débil $y$ una periferia de grandes señores, duques $y$ marqueses, relativamente fuerte. No está de más recordar que hubo momentos en la historia de Europa en que esta periferia tenía su propio sistema fiscal, sus aduanas, ejércitos y sistemas de pesos $y^{\prime}$ medidas. Esto no ocurrió en América Latina. Aquí hubo -y los hay aún - terratenientes tiránicos y caciques locales inescrupulosos, pero sólo en muy contadas ocasiones -y nunca con resultados duraderos- han podido desafiar exitosamente el poder ejercido por el centro. Estos caciques regionales incluso cuando parecieron más prósperos e influyentes, o más decididos a clesafiar el poder central, fueron casi sin excepción usuarios eficientes de las migajas de poder que caen de la mesa central, o políticos resentidos con la pérdida de los favores del gobierno metropolitano ${ }^{5}$.

El sistema paternalista y centralizado que regía la vida política de nuestra América en forma minuciosa y legalista desde los centros burocráticos de la peninsula, se mantuvo en relativo buen funcionamiento -atendiendo a la inmensa extensión de los territorios que cubría- durante tres siglos. Las dificultades de comunicación no fueron suficientes para atenuar el control que emanaba desde Madrid donde hubo poder suficiente para dar fuerza a los brazos administrativos más largos de la cristiandad. El proceso de descomposición que terminó con el desmembramiento del Imperio, a partir de 1810 no significó un cambio substancial en esta modalidad centralista y paternalista puesto que las revoluciones de la Independencia no sólo fueron planteadas en primera instancia como esfuerzos legitimistas, sino que al adquirir eventualmente un carácter abiertamente separatista, el centralismo madrileño pasó sin mayor atenuación a cada una de las respectivas capitales latinoamericanas: Mréxico, Lima, Bogotá y San-

do - con más o menos éxito- la abundante y compleja legislación existente. No es sólo coincidencia que en fecha tan temprana - para América Latina- como 1511 -emergiera en España el Consejo de Indias que era primordialmente un cuexpo legal y que durante todo al primer período de conquista y consolidación fuera cl abogado letrado el personaje más leal, más importante y más respetado de los servidores de la corona en América. "La más seria obligación que su Majestad reconoce en sus nuevos territorios de Indias es la de proveer justicia abundante", es una frase recurrente que refleja fielmente el estilo e intención de la monarquia paternalista. Ver John H. Parry, op. cit., pp. 192-195.

'Sobre esto, ver José Carlos Mariátegui, Siete ensayos de interpretación de la realidad peruana, Santiago, 1955, pp. 144-169. 
ciago, y cada una de las metrópolis locales, tomaron firmemente en sus manos las riendas que habia aflojado la península. No está de más anotar que en cierto sentido los movimientos de 1810 tienen más en común, por ejemplo, con el separatismo de Mrr. Ian Smith en la Rhodesia de hoy, que con movimientos genuinamente revolucionarios tanto en lo social como en lo político.

\section{EL GENTRALISMO RELIGIOSO}

El centralismo vertebral de nuestra tradición política se refleja también en el ámbito religioso. Aun cuandro en varios países de América Latina ha existido durante mucho tiempo una robusta y compleja actitud. anticlerical -basta recorclar los ejemplos de México, Argentina $y^{\prime}$ Chile- en ninguna de nuestras naciones ha tenido éxito la disidencia religiosa sistemática. No viene al caso entrax a cliscutir en este momento si acaso la disidencia religiosa es o no un ingrecliente principal del liberalisno $\mathrm{y}$ del socialismo europeo, pero es muy dificil imaginar la tradición liberal y socialdemócrata del hemisferio norte en la ausencia cle una actitud latitudinaria en materias cle religión ${ }^{0}$. En América Latina, sin embargo, el problema ni siquiera alcanzó a plantearse puesto que nunca hemos tenido nada comparable con el fenómeno de la disidencia religiosa europea: la autoriclad del catolicismo nunca ha siclo clesafiada descle adentro. Indudablemente ha habido fuertes movinientos anticlericales, pero iglesias incendiadas y sacerdotes asesinados no constituyen una alternativa viable al poder religioso central. La extraordinaria resistencia y capacidad de supervivencia del catolicismo oficial se debe en parte a su Alexibilidad, pero también en parte importante a esta ausencia de desafíos significativos. He aqui, por ejemplo, el caso de Miéxico, nación en la que varias generaciones de revolucionarios han hecho del anticlericalismo un aspecto principal de sus postulaclos y que incluso hoy día estima más llevadero mantener relaciones diplomáticas con Cuba que con Ia Santa Sede y donde, sin embargo, el catolicismo mantiene sin mayor dificultad su calidad de iglesia absolutamente mayoritaria.

La solución de este falso dilema es sencilla: las religiones complejas, así como las ideologías y sistemas filosóficos, sólo admiten comparación, y por ende, desafio, cle sistemas equivalentes y alternativos. El anticlericalismo no es una religión, como el Metodismo inglés o el Presbiterianismo escocés: ni siquiera admite las reglas del juego y por

"En esto me apoyo en el magistral estudio de R. H. Tawney, Religion and the Rise of Capitalism, London, 1926, especialmente el capitulo cuario. 
consiguiente no constituje una alternativa viable. Si de jugar ajedrez se tratara, el anticlericalismo sería el equivalente de clarle un manotazo al tablero y echarlo al suelo con toclas sus piezas: de ningún modo puede esto ser descrito como un gambito triunfante.

Cabe agregar que en la tradición histórica clel ámbito noratlántico, la clisidencia religiosa recibió fuerte apoyo popular en las regiones industrializadas. Incluso hoy día se observa que aquellas regiones de las Islas Británicas cloncle prevalecen las clenominaciones disidentes son también aquellas más afectadas por la Revolución Inchustrial. De la disiclencia religiosa - dentro de un ámbito de tolerancia- a la clisidencia política, hay una clistancia muy corta y no precisa de excesiva erudición el descubrir el ancestro religioso de la gran mayoría de los movimientos políticos reformistas y revolncionarios que surgieron en el hemisferio norte durante el último siglo.

Hoy clía en América Latina es muy claro que existen clisensiones internas en el catolicismo; pero antes que desacuerdos que pudieran llevar a un movimiento clisiclente en lo religioso, éstas reflejan inquietudes sociales y políticas y no es fácil ver cómo pudieran éstas evolucionar de modo tal que desembocaran en planteamientos doctrinarios religiosos alternativos. Incluso el notable crecimiento del protestantismo durante las últimas clécadas no alcanza a constituir una alternativa de significación, por lo menos a corto plazo: en Chile y Uiuguay que tienen las minorías no católicas más importantes, los protestantes no superan el diez por ciento de la población.

\section{EL OENTRALISMO ECONOMICO}

A la tradición centralista en política y religión, hay que agregar la robusta tradición centralista en el ámbito económico, derivada en parte de la península y reforzada por las circunstancias especiales que han acompañado a la inclustrialización de nuestra América Latina.

En la Europa de Ios siglos cliecisiete y' dieciocho, cuando se generó el capital y las actitudes industriales modernas que llevaron a la Revolución Industrial, la acumulación de capital inclustrial fue el resultado marginal de una manera de vivir y los primeros centros dinámicos de decisión en este ámbito fueron geográfica $y^{\prime}$ políticamente periféricos, es decir, alejados de las fuentes del poder político central. Los artesanos puritanos que perfeccionaron los métodos de fundición del hierro y el acero vivían en condaclos fronterizos con Gales, rara vez habian visitado Westminster y no tuvieron apoyo estatal para la prosecución de sus tareas. Su laboriosidacl era el reflejo de una con- 
vicción religiosa y no huljiera variaclo de haber sido apoyada o disuadida desde Londres. La intervención del Estado central en el proceso de la industrialización de las naciones de Europa fue tardío y vacilante y no alcanzó a reflejarse sino muy excepcionalmente en los modelos de interpretación no revolucionarios que enmarcaron la comprensión intelectual $\mathrm{y}$ política del proceso ${ }^{\top}$. Finalmente, puede observarse que la incorporación de las nuevas técnicas industriales en forma masiva a la sociedacl europea reforzó considerablemente la posición de poder de la burguesía inclustrial y generó a la vez una nueva clase proletaria industrial que habría cle desempeñar un papel de importancia señera durante los siglos diecinueve $y^{\prime}$ veinte.

Ninguna de estas consideraciones parecen tener aplicación en el caso de América Latina. Aquí la industrialización ha sido un proceso de substitución de importaciones causado principalmente - $y$ en forma casi accidental- por factores externos como la crisis de $1929 \mathrm{y}$ la Segunda Guerra Mundials. La tecnología industrial necesaria para llevar adelante este proceso ya habia progresado lo suficiente para poder ser descrita como esencialmente capital-intensiva, necesitando de una fuerza cle trabajo relativamente reducicla, mejor entrenada $y$ recibiendo salarios relativamente elevados: a todas vistas un conglomerado diferente de aquel que los analistas de la segunda mitad del siglo diecinueve en Europa tenían en mente cuando usaban la frase "proletariado inclustrial". Además esta tecnologia avanzada fue incorporada por una sociedad que ya poseía con mucha anticipación, una civilización urbana preindustrial compleja. Las clecisiones que llevaron - cualesquiera las causas - a la rápida industrialización de gran parte del ámbito latinoamericano, no fueron de origen periférico sino que originaron clel poder central estatal y fueron apoyadas decididamente a través de programas de subvenciones, tarifas discriminatorias, canalización de créditos y políticas de fomento industrial administradas por

'Desde luego hay excepciones, Friedrich List, por ejemplo, empezó a publicar su influyente Sistema nacional de economia polftica, en 1841, pero sus ideas no fueron adoptadas sino hasta clespués de su muerte acaecida en 1846.

${ }^{8}$ Los efectos de la crisis de 1929 en la iniciación del proceso de industrialización masiva fucron particularmente importantes en Brasil, ver Celso Furtado, The Eco* nomic Growth of Brazil, University of California Press, 1963, pp. 203-224.

'Desde luego en los principales países de América Latina existía un movimiento sindical fuerte y militante, cosa que no ocurrió en Europa durante la primera época del cesarrollo inclustrial. La nueva fuerza de trabajo industrial se incorporó sin mayores dificultades dentro, de este inarco sinclical, lo que le permitió desde un principio defender niveles de ingreso superiores a los que obtuvieron, por cjemplo, los trabajadores industriales britinicos o belgas al iniciarse la industrialización de esas naciones. 
agencias estatales ${ }^{10}$. No fueron, en consecuencia, ni el producto de las actividades de una burguesía industrial extraestatal de corte clásico, ni generaron el desarrollo de una burguesía moderna, vanguardista, reformista y nacionalista cle ese tipo ${ }^{11}$. De ahí que los cambios sociales y políticos tradicionalmente asociados con la Revolución Industrial europea y que muchos esperaban que se reprodujeran en América Latina, no se han realizado; ha habido muchos cambios, sin duda alguna, pero estos escapan de los modelos europeos y obedecen a factores intrínsicamente latinoamericanos que aún esperan un esfuerzo de estuclio, análisis e interpretación general que incorpore lo acaecido en nuestro continente en toda su rica particularidad.

El centralismo tradicional, reflejado significativamente en lo polftico, lo religioso y lo económico, ha llegado hasta nuestros días ${ }^{12}$. Las

\footnotetext{
${ }^{10}$ Esta generalización - como todas las que se xefieren a América Latina- admite excepciones. Es claro que el papel de la empresa privada en Venezuela y Colombia, ha sido más importante, por ejemplo, que en Brasil, México y Chile, pero subsiste la duda de si hubieran podido hacer todo lo que hicieron sin apoyo estatal.

"Para un análisis más detallado de cste punto, ver Claudio Véliz, Ed., Obstriculos para la transformación de América Latina, Fondo de Cultura Económica, Mexico, 1969, Introducción.
}

"Conviene advertir que durante el siglo $\mathrm{xix}$ nuestras naciones se apartaron perceptiblemente de esta tradición centralista como resultado, en parte, de la extraordinaria prosperidad económica de sus grupos rectores, especialmente durante la segunda mitad del siglo y hasta la postguerra de 1918. La prosperidad resultante de las grandes exportaciones de productos primaxios actuó como una especie de lubricante que eliminó las fricciones entre una superestructura dependiente en lo cultural, lo político $y$ lo económico que obedecía al anhelo entusiastamente expresado de aquellos grupos rectores de imitar a Europa en todo sentido. Así se importaron planteamientos filosóficos (el Positivismo, por ejemplo), doctrinas politicas, arquitectura, modas en el vestir, muebles, sistemas educacionales, etc. Pero bajo gruesas capas de cultura europea importada, permanecia latente la fuerte tradición centralista nuestra quc hubo de aflorar cuando la crisis de 1929 eliminó el lubricante y obligó a los latinoamericanos a considerar con severidad y urgencia la verdadera naturaleza de sus sociedades y los instrumentos disponibles para mejorarlas.

Esta experiencia no ha sido excepcional, considérese por ejemplo, el caso de Turquía. La aspiración suprema de los reformadores liberales del siglo xix fue la de transformar a esa nación en una monarquía constitucional europea. Esto lo consiguieron teóricamente en 1876 con una constitución copiada prácticamente verbatim de la constitución de Bélgica. Esta constitución fue suspendida por Abdulhamid en 1878 pasando a ser el símbolo del movimiento de Ios Jóvenes Turcos que, triunfan. tes en 1908, procedieron a restaurarla. Fue sólo durante la década de 1930, qur Turquia aceptó la responsabilidad de gobernarse con instrumentos propios surgidos de la comprensión cabal de la relación eficiente que debia existir entre sus aspiraciones reformistas y modernizadoras y su tradición histórica. Ver, Bernard Lewis, The Emergence of Modern Turkey, Oxford University Press, 1968, pp. 362363. 
cuatro experiencias revolucionarias más importantes de este siglo han tratado de reconstruir el edificio institucional obedeciendo a planteamientos doctrinarios notablemente diferentes, sin embargo todas, en menor $b$ mayor grado, se han movido hacia la institucionalización de regímenes de partido único. El PRI mexicano se ha transformado en un verdadero símbolo centralista por derecho propio; el régimen cubano, luego de algunas vacilaciones preliminares, ha desembocado asimismo en un sistema de partido único y la explicación de esto, a mi entender, está más relacionada con el hecho de que Cuba participa absolutamente de la tradición centralista latinoamericana que con su novedoso comunismo. La revolución boliviana también hizo un esfuerzo importante por establecer un régimen de partido único alrededor del MeNR; el que esto fracasare aparentemente no disminuye la significación del intento $y$ no está de más anotar que el actual Gobierno de Bolivia no ha tratado con mucho entusiasmo de alejarse del centralismo de sus predecesores. El caso del Perú es igualmente decidor mientras que la tendencia que se percibe en otros países de la región, incluso aquellos con regímenes democráticos pluripartidistas $\mathrm{y}$ de gran sofisticación, es claramente hacia un incremento del poder central del estado.

En las recientes elecciones presidenciales chilenas, las tres candidaturas - desde puntos de vista abiertamente discrepantes- coincidian en demandar mayor poder central, ya sea a través de modificaciones de la Constitución, ya sea entregando crecientes atribuciones y responsabilidades al sector estatal en materias económicas y sociales.

Esta tradición centralista latinoamericana corre paralela -en nuestros días- con una tendencia mundial hacia una mayor intervención estatal en los asuntos públicos que es a su vez uno de los resultados del desarrollo de las técnicas administrativas y de comunicación; documentación y computación. Pero mientras en países como Estados Unidos, Australia o Gran Bretaña, tales tendencias chocan contra un marco conceptual pluralista, periférico en la distribución del poder y más bien liberal en su apreciación de la responsabilidad política, en America Latina no hace sino reforzar la corriente que nos mueve hacia un incremento cuantitativo $y^{\prime}$ cualitativo del control central.

De este modo se explica, en parte, por qué el hábito institucional clel compromiso entre centros alternativos $y^{r}$ coexistentes de poder político no tiene una significación esencial en la tradición histórica de América Latina: la necesidad persistente que obligó a los centros de poder europeos — hasta el día cle hoy- a negociar equilibrios cam- 
biantes con una periferia relativamente fuerte es de menor importancia en esta parte del mundo.

\section{UNA COMPLEJA TRADIGION DIPLOMATICA}

El segundo factor de continuidad que considero importante se refiere a la peculiar tradición diplomática de nuestros países durante las décadas de vida republicana. Me parece razonable sugerir que de esta tradición surjen actitudes, hábitos, tendencias y experiencias funcionales que contribuyen notablemente a diferenciar a nuestras naciones de aquellos países medianos y pequeños que, al entender de algunos, constituyen un llamado Tercer Mundo, $y^{\prime}$ que sólo en fecha muy reciente han debido aceptar la responsabilidad de dirigir su política exterior, y esto, bajo la sombra de la ingerencia universal de la Guerra Fría. Además, estimo que tomada conjuntamente con nuestra tradición centralista, este segundo factor de continuidad relativa contribuye también a clelinear una situación cualitativamente diferente de aquella en que se encuentran la gran mayoría de los países medianos y pequeños del munclo actual.

Durante los trescientos años de la Colonia, la aspiración del liderazgo político, económico $y^{\prime}$ social de los dominios de la corona, exa ser como los españoles; imitarles, aspirando al reconocimiento que entregaban su confianza en cargos de responsabilidad; quizás aspirar al elevado honor de ser recibido por la corte peninsular. Las circunstancias que acompañaron la emergencia de nuestros países de aquel estado de vasallaje - una revuelta inicialmente legitimista seguida de una cruenta y prolongada contienda armada - determinaron un rechazo psicológico y político en contra de la metrópoli que se reflejó en la búsqueda de otros horizontes europeos para las nacientes repúblicas. De este modo, en lugar de un nacionalismo introspectivo, creció en nuestro ámbito intelectual una leyenda negra que obcurecía todo lo acontecido antes de 1810 y glorificaba todo lo acaecido descle entonces. Tal actitud tendió a cercenar - sin un éxito definitivo, por supuesto- nuestras raíces históricas y resultó en una natural gravitación hacia otros centros creativos, especialmente aquellos de la Europa que se movía hacia la cúspïle de su influencia política $y$ económica sobre el mundo contemporáneo. Hubo, desde luego, quienes intentaron encontrar en la América precolombina la simiente que dinamizara $y$ vertebrara las tareas de la construcción de las nuevas naciones, pero estos esfuerzos escasamente tienen un valor anecdótico y simbólico que no alcanzó a echar raíces fuertes. Es posible sugerir, 
por consiguiente, que nuestra América salió cle una clependencia cultural para sumergirse en otra; se trataba entonces, rechazando todo lo hispánico, de ser como los admirados franceses o británicos. Vestirse como ellos, imitarles en la conclucción cle los asuntos públicos; adoptar con entusiasmo sus métodos educacionales, su ciencia y su tecnologia; construir casas, pintar cuadros $y^{\prime}$ componer música como ellos, incluso, pensar como ellos. Quizis un poco injustamente, esta actitud europeizante ha pasado a ser simbolizacla por aquel famoso subtítulo de la primera edición del Fíacundo, de Domingo Faustino Sarmiento que planteando el dilema, civilización y' barbarie, determinó para muchos que ni siquiera leyeron el libro, las alternativas abiertas para el nuevo latinoamericano ilustrado; ser como los europeos era ser civilizado, ser como nosotros, era ser bárbaro.

La aristocracia bonaerense se eclucaba en inglés $y$ la de Caracas, en francés; la clistancia cultural era brevísima entre Lima y París o entre Santiago y Londres, pero la distancia geográfica y política era vasta y América Latina apenas si se perfilaba muy tenuamente sobre el horizonte político cle las cancillerías europeas ${ }^{13}$. Los sistemas de equilibrio de poder del viejo continente no incluian en parte alguna a los países de América Latina; la compleja orquestación del "concierto emropeo" no incluía ni instrumentos ni melodías latinoamericanas. La distancia, incluso luego del perfeccionamiento de la navegación a vapor, era enorme $y$ se erguía como frontera tremencla e insalvable ${ }^{1 t}$.

Aclemás, las circunstancias contemporáneas que afectaban la política externa de las Grandes Potencias, se tradujeron en una especie cle "pausa imperial" que coincidió con el perfoclo durante el cual las repúblicas nacientes empezaron a estructurar sus políticas externas. Gran Bretaña había perdiclo mucho cle su entusiasmo por las aventuras extranjeras luego clel fiasco de la Inclependencia de Estados

${ }^{23}$ Es notorio que cuando bajo el Ministerio del Barón de Rio Branco, el Brasil efectuó su famoso viraje político externo, alejándose de Europa y cstableciendo una "rclación especial" con Estados Unidos, en el vicjo continentc, decisivo cambio politico pasó desapercibido, ver, E. Bradford Burns, The Untwitlen Alliance, Rio Branco and Brazilian-American Relntions, Columbia University Press, 1966, p. 181.

"Esta "tiranfa de la distancia" afcctó cle modo muy diferente, por cjemplo, a las posesiones britinicals que se encontraban en circunstancias comparables. Ver, por cjemplo, el cxtraorclinariamente lúciclo e importante estudio del historiador atustraliano Geoffey Blainey, The Ty'rumy of Dislance, Melboume, 1966. Desde luego, a pesar cle la distancia y del grado significativo de autonomía obtenido por los estadlos australianos antes de la Seguncla Gucrra Mundial, esto no se reflejo en la polftical de clefensa $y^{\prime}$ en la conducción de los asuntos exteriores. 
Unidos y de la larga $y^{\prime}$ costosa guerra contra Francia $y^{\prime}$ la opinión pública británica consideraba a las colonias como fuentes inagotables cle gastos que debfan al fin de cuentas ser pagados por los contribuyentes de la metrópoli15. Respecto de América Latina, Gran Bretaña no tuvo pretensiones de expansión territorial, cuidándose, sin embargo, de no permitir que otras potencias europeas cayeran en la tentación de llenar el vacío que dejaba su relativa indiferencia ${ }^{16}$. Más adelante, el resurginiento de interés por la India y el Lejano Oriente manturo al coloso británico efectivamente alejado de nuestras costas. Igual cosa ocurrió con Francia, que, abrumada por el desastre de la aventura bonapartista en México y ocupacla con su confrontación con Prusia, no turo ni la inclinación ni la capacidad real para pretender extender su influencia sobre América Latina. Claro está que estas limitaciones no fueron absolutas puesto que el control francés sobre la Cochinchina se concretó precisamente clurante la década de 1860 , aunque aparentemente el esfuerzo marcó los límites de lo posible en las circunstancias.

En cierto sentido $-y^{\prime}$ para establecer una comparación lícita-, tanto el Japón como la América Latina usufructuaron, de modo diferente, de esta "pausa imperial" que cesó con la rápida e inescrupulosa colonización de Africa por las Grandes Potencias que, por

15"From the point of vicw of the mother country territorial sovereignty over these vast and distant spaces was a privilege for which the taxpayer was heavily' charged at a time when the British exchequer had to meet interest on war debts and the transition from war to peace. Thus the colonies seemed merely a burden. This attitude lasted for half a century and indeed reached its climax after $1850 .$. The new industrial cconomy in its earlicr stages discounted the value of an empirc. to serve an outworn mercantilist system. Free traders had no use for colonies, and for a long time the colonial market was small and unimportant". Ver, Sir Llewellyn Woodward, The Age of Reform, 1815-1870, Oxford University Press, 1962, pp. 365-366.

10Ver, Burr, op. cit, p. S. Esta actitud de Gran Bretaña se manifestaba hasta en incidentes de menor importancia. Por ejemplo, durante el año 1829, hubo negociaciones de nivel sccundario entre oficiales franceses $y$ ' representantes chilenos respecto de concesiones para aprovisionamientos navales que Francia descaba obtenex en la isla de Chiloci. Estas negociaciones fueron eventualmente interrumpidas por Chile, pero antes de que esto se supiera en Gran Bretaña, el Ministro de Relaciones Exteriores, Lord Aberdeen, cnvió uni comunicación reservada sobre el particular al Cónsul Británico interino en Valparaiso, explicando que el Gobierno de S. M. B. se oponia alssolutamente a cualquier concesión y que si Chile acordara entregar: las concesioncs solicitadas por los franceses, Gran Bretaña se vería obligada a postergar el reconocimiento diplomítico de la independencia chilena. Ver, Foreign Office papers, F.0./16, vol. 9, fols. 3·6, Public Record Office, Londres. 
añadidura, nuevamente contribuyó a alejar de América Latina la atención expansionista de Europa.

De este modo, la distancia y la buena suerte se unieron para que nuestras naciones quedaran relativamente al margen de una politica mundial que se caracterizó - si se toma el período entre la Guerra de Crimea y la Primera Guerra Mundial- por una tendencia imperialista y la división del mundo extraeuropeo en colonias y zonas de influencia directa. Era improbable en estas circunstancias que la diplomacia de las jóvenes repúblicas gravitara principalmente hacia los asuntos políticos mundiales: por lo menos es razonable suponer que una dosis de sentido común bastaba para impedir que esto sucediera. Lo que sí tuvo lugar, fue una fuerte canalización y concentración del interés de nuestras cancillerías hacia los asuntos políticos intralatinoamericanos. A esta tarea, nuestros diplomáticos del siglo pasado aportaron un instrumental variaclo e impresionante; desde luego, casi sin excepción, quienes practicaron la cliplomacia exan hombres ilustraclos y conocedores de toda la compleja gama de activiclad política internacional tal cual se practicaba descle las cancillerías de las Grandes Potencias. Aparte del ritual de la cliplomacia - del cual gustaban $y$ practicaban con entusiasmo $y$ en un francés muchas veces impecable - utilizaron su entrenamiento, casi inevitablemente jurídico, en aplicar y a veces innovar, sobre los diversos procedimientos legales utilizados en las transacciones internacionales.

Se creó de este modo, en nuestra América Latina, una especie de microcosmos de la política mundial. Durante el centenar de años que precedió a la Segunda Guerra Mundial, las relaciones entre las naciones de esta parte del mundo, pasaron por todas las complicadas variaciones del arsenal conceptual e instrumental desarrollado en Europa; hubo guerras internacionales, arbitrajes, pactos secretos, sistemas de equilibrio de poder, coaliciones defensivas $y$ ofensivas $y^{\prime}$ variaciones sobre cacla uno de estos temas. En apariencia y realidad, quienes practicaron la cliplomacia en América Latina durante esas décadas, dominaban las formas de esta disciplina en forma consumada, pero existía entre las formas diplomáticas y la apreciación de lo que constituía el interés nacional, que, al fin $y^{\prime}$ al cabo, es el que determina la conducción de los asuntos externos, una relación anómala: la distancia geográfica y política obligaba a clirigir la atención de las cancillerías hacia los negocios intralatinoamericanos, mientras que la estrecha relación cultural con Europa que clominaba la vicla cloméstica al nivel de los grupos rectores de nuestros asuntos públicos, generaba clefiniciones del interés nacional que eran francamente de- 
pendientes. Si se acepta que la política exterior de cualquier pais refleja generalmente la apreciación que su liderazgo tiene de lo que constituye este interés nacional, entonces es posible concluir tentativamente que el complejo virtuosismo de la diplomacia latinoamericana de la época fue víctima de esta clependencia. Quizás a riesgo de exagerar un poco, se podria sugerir que la aspiración de nuestras cancillerias exa hacer de América Latina una pequeña Europa e incluso cuando las naciones de más peso se apartaron de la tutela voluntaria del viejo continente - Brasil, bajo el liclerazgo de Río Branco, por ejemplo- lo hicieron para buscar otra gran potencia a cuya sombra pudieran albergarse ${ }^{17}$.

A pesar de esto, subsiste la valiclez instrumental de la tradición diplomática intralatinoamericana como factor cle continuidad funcional. En todo el ámbito que rodea al Océano Pacífico, sólo Rusia y Estados Unidos tenian políticas exteriores estructuradas funcionalmente con anterioriclad a las naciones del Pacto Andino. Incluso el Japón sólo se incorporó al ámbito internacional a mediados del siglo cliecinueve mientras que naciones de la importancia de Australia enviaron sus primeros embajaclores al exterior a fines de 1939 -ciento veinte años después que Colombia, las IProvincias Unidas del Río de la Plata y Chile enviaron sus primeros ministros plenipotenciarios a las grandes capitales europeas. Más aún, la conclucción cle los asuntos externos y de clefensa de Australia, dependieron directamente de Gran Bretaña prácticamente hasta comienzos de 1942, cuando el Primer Ministro John Curtin adoptó - por primera vez- una decisión que contrariaba directamente los deseos del Gobierno británico ${ }^{18}$. Cabe

"Sobre esto, ver el excclente estudio de E. Bradford Burns, "To strenghten the friendship between Brazil and the United States was one of the basic objectives of Rio Branco's forcign policy. Building upon cxisting foundations, the foreign minister succecded in diplomatically aligning the two nations...", p. 76, and... "Foreign reactions to the shift of Brazil's diplomatic axis from Europe to the United States varied considerably: in Europe it seemed to have gone unnoticed... while in South America, sensitive to all subtleties, real or imagined, of continental diplomatic maneuverings, the change was noted almost at oncc. Chile, Brazil's closest South American friend, accepted, even welcomed, the rapprochement: Argentina, Brazil's chief rival, reacted adversely...", p. I8I.

18"At the time of Munich Australia, unlike Canada and South Africa, had no diplonatic missions in any foreign country. Despite the rc-establishment in 1935 o a small and sepirate Department of External Affairs, and recruitment for this department of a few officers with overseas experience and training, Australia háal as yel no sufficiently organised Foreign orfice supported by diplonatic establishments overseas to provide essential information and comments necessary for: the formulation of a distinctively Australlian foreign policy" Sir Alan Wratt, 
anotar que aquella decisión del Pxemier Curtin, estuvo intimamente - y en forma característicamente pragmática- conectada con su convencimiento de que la clefensa de Australia dependería de ahi en aclelante, principalmente de Estados Uniclos ${ }^{10}$. En cierto modo, el cambio de orientación de la política exterior cle Australia en 1942 es comparable con aquel cambio de orientación de la política del Brasil mencionada más arriba. Es sólo en fecha muy reciente y quizás en forma importante como consecuencia de la decisión británica y estadounidense de atenuar su presencia militar en la región del Sureste asiático, que Australia se ha visto en la necesiclad cle iniciar la formulación cle una política exterior propia, que no sea necesariamente el reflejo simpático cle la política externa de potencias aliadas.

Es includable que comparada con las experiencias de naciones como Japón, Australia, Ganadá y N'ueva Zelandia - de importancia señera en la región del Pacffico, la compleja y larga tradición diplomática de las naciones signatarias del Acuerdo de Cartagena, presenta características que la cliferencian notablemente. En cuanto a las otras

The Evolution of Auslralian Forcign Policy, 1938-1965, Cambridge University Press, 1967, pp. vil-vil. Más adelante, en pp. 24-25, agrega: “the Prime Minister (Men. zics) was not making on bchalf of Australia, a declaration of independence of F-ritish loreign policy... rathcr... he held to the view expressed by him in the Iouse of representatives on 5 October 1938, namely that the British Empire cxcercises its greatest influence in the world... when it speaks with one concerted voice. This interpretation is supperticd hy the Note handed by the British Embassy to the State Departmcit on 50 November 1939, in connexion with the appointment of Casey as first Australian Minister to Washington, which includes the sentence: "This arrangement was not to denote any departure from the diplomatic unity of the Empire...".

${ }^{10} \mathrm{E} 10$ de diciembre de 1941, la aviación japonesa atacó y hundió los acorazados británicos Prince of Wales y Repulse, frente a la costa malaya; el 26 de diciembre, la guarnición británica y canadiense en Hong Kong se rinciió ante el avance japonés; otro ejército japonés avanzaba ya sobre la provincia de Iohore y sólo la fortaleza de Singapur ofrecfa una línea de defensa para Australia. El 29 de diciembre, el Primer Ministro John Curtin se dirigio a sus conciudadanos explicanco, “...sin inlibiciones de ninguna especie, quiero dejar abundantemente claro que Australia mira ahora hacia Estados Unidos (para su defensa)... dedicaremos toda nuestra energía a la preparación de un plan, con Estados Unidos como piedra angular, que permita a nuestro país rccobrar la confianza de ser capaz de resistir hasta que cambie el curso de la guerra $y$ se pueda derrotar al enemigo...". Menos de dos mesce más tarde, se rendfa Singapur y dos dís después, en una decisión sin precedentes, el Cobicrno australiano rechazaba una colicitud británica de enviar la Séptima División Australiana al teatro bélico de Birmania, optando por retonarla a Nustralia para defencler su territorio contra el inminente ataque japonés. Ver, Manning Clatk, A Short History of Altstralia, Sydney, 1963, pp. 224 et seqq. Tam. bièn O. H. K. Sphtc, Australia, Melbourne, 1968, pp. 01.93. 
naciones de la región; Filipinas, Malasia, Singapur, Indonesia, Tailandia, Corea y China, indudablemente ya sea por lo reciente de su creación como estados independientes o por la naturaleza especialísima de su posición en el contexto internacional, se diferencian también significativamente del contexto histórico reciente que ha marcado el desarrollo de la política exterior de los paises andinos.

GEOPOLITIGA CENTRIPETA ENTRE LOS ANDES Y EL PACIFICO

De prosperar la iniciativa suscrita en el Acuerclo de Cartagena por Colombia, Perú, Ecuador, Bolivia y Chile, esta coalición tendrá la singular distinción, entre aquellas que tienen vigencia real en el mundo contemporáneo, de reclamar una de las tradiciones históricas más antiguas. El apreciar selectivamente los hitos que pueden conducir a la clefinición de una traclición política de gravitación centrípeta a través de varios siglos es un ejercicio riesgoso; sin embargo creo que en este caso, las generalizaciones tienen validez para sugeril un grado de continuiclad eficiente que tiene significación contemporánea.

El que un ámbito geográfico tenga límites naturales claros y coherencia interna adecuada, -en cuanto a facilidades de comunicación, recursos accesibles y' otros factores- no basta para que dentro de él existan conglomerados sociales igualmente integrados descle un punto de vista político y cultural. Las islas británicas, por ejemplo, son pequeñas y compactas, pero clentro de ellas existen por lo menos tres culturas diferentes que incluso hoy, bajo el Reino Unido, no han alcanzado un grado suficiente cle integración, por lo menos a juzgar por la opinión de algunos de sus integrantes. Las llanuras europeas han estado habitadas por muchos pueblos de muy diversa cultura política cuyas fronteras han cambiado con frecuencia; los valles alpinos de Suiza encierran asimismo a numerosos grupos culturales con un grado extraordinario de diferenciación. Los ejemplos pueden multiplicarse, sin embargo, en el caso de los pueblos que durante muchos siglos han vivido en los valles y mesetas encerrados entre el macizo andino y el Océano Pacifico, parece haber existiclo una propensidad interesante hacia la estructuración de regímenes politicos que extienden su dominio entre ambas fronteras naturales. Acerca de esto no hay, evidentemente, nada inevitable ni absolutamente necesario, pero no deja de llamar la atención el que existan cuatro instancias históricas, distribuidas a través de más de mil años, del establecimiento 
de regímenes, si no culturalmente homogéneos, por lo menos con un control apreciable sobre toda la extensa geografía que se extiende entre los Andes y el mar.

Existe controversia acerca de la cronología de la época preincaica, pero para nuestros propósitos basta establecer que en alguna fecha entre 300 d. C. y' 1100 d. C. las culturas cle Tiahuanaco extendieron su influencia sobre gran parte de la región andina. Este control llegó bastante más lejos durante el incario y' durante las décadas que precedieron el arribo de los conquistaclores españoles, el imperio cubría prácticamente todo el ámbito habitado desde el sur, de lo que hoy es Colombia, hasta las riberas clel rio Maule, en el sur de Chile. Cualesquiera la incertidumbre respecto de fronteras verdaderas y cronología, parece claro que entre las culturas de Tiahuanaco y el incario, hubo una instancia histórica que estableció un solo clima cultural y político para la región andina.

El segundo hito de esta continuiclad macrohistórica, lo constituiría el régimen virreynal que a través cle trescientos años, con variaciones determinadas por las necesidacles administrativas clel imperio, cubrió la mayor parte del territorio que hoy ocupan las naciones que firmaron el Acuerdo de Cartagena. El área administrativa clel Virreynato del Perú no correspondió exactamente con las fronteras actuales de las naciones del Pacto Andino, pero como ámbito de gravitación política, es indudable que aquel fue el mismo del incario y el mismo de nuestra época. En cuanto a la gran diversidad de manifestaciones culturales dentro de tan vasta región, puede observarse que el elemento integrador lo constituyó la incorporación de la cultura española que estableció una lingua franca, una práctica administrativa centralizada, un régimen monetario y un control político aceptado genevalmente a través de todo el virreynato y sus divisiones subordinadas durante casi tres siglos.

Un tercer hito en esta continuidad histórico-geográfica lo constituye la formación del sistema de equilibrio de poder de la costa sudamericana del Pacífico clurante el siglo cliecinueve ${ }^{20}$. Los movimientos de independencia en América Latina tuvieron durante sus primeras etapas un carácter continental que ocultó por lo menos momentáneamente la diferenciación muy clara que existía entre las antiguas

${ }^{30}$ Seguramente los estudios mís importantes que se han publicado acerca de los problemas del cquilibrio de poder en América del Sur, son aquellos del profesor Robert N. Burr, de la Universidad de California. En los párrafos que siguen se hace uso -quizás indebido- de muchos de los resultados de sus estudios y quiero expresar aqui mi sincero reconocimiento. C. V. 
colonias españolas y el graclo elevaclo cle complejidacl cultural y con. ciencia cle formar entidades nacionales separadas. Estos sentimientos se acentuaron en las postrimerias de la lucha contra España y adquirieron especial prominencia clurante el difícil proceso de determinar las fronteras de las nuevas repúblicas. Aquellas naciones independientes que se habian formado sobre la base cle los antiguos centros virreynales no tuvieron mayor dificultad en establecer su hegemonía sobre la parte principal de los territorios que anteriormente habian estado bajo la administración colonial. Tal fue el caso de México, Colombia, Perú $y^{\prime}$ las Provincias Uniclas clel Río de la Plata. Entre éstos, sin embargo, $y^{\prime}$ especialmente en América del Sur, había grandes porciones de territorio inadecuadamente explorado doncle la aclministración española no se había preocupaclo de establecer límites precisos ni entre sus propias divisiones administrativas, ni entre éstas y aquéllas controladas por la corona portuguesa. Así se generaron conflictos de importancia que determinaron primero la estructuración de dos sistemas de equilibrio de poder, uno alineado sobre la costa clel Atlántico y que inclúa por lo menos al Brasil, Uruguay, Paraguay'. y Argentina; y otro sobre la costa del Pacífico e incluyendo a Colombia, Ecuaclor, Perú, Bolivia y Chile. Hacia fines clel siglo, éstos dos sistemas tenclieron a integrarse en uno solo, con una frontera conflictiva de especial sensibilidad entre Argentina y Chile. El hecho concreto es que los países que ahora forman el Grupo Anclino mostraron una muy clara tendencia a establecer un régimen de coordinación interna, aún cuanclo ésta no fuera sino la resultante de rivalidacles $y^{\prime}$ temores comparticlos.

Finalmente, una cuarta instancia histórica la constituye evidentemente la firma del Acuerdo cle Cartagena por las cinco naciones andinas. De ser acloptada la hipótesis de trabajo respecto cle la existencia cle una tendencia cen trípeta en el ámbito enmarcado entre las montañas y el Pacífico, la firma clel compromiso anclino no podría ser considerada como un evento improvisado o accidental, sino como una manifestación histćrica contemporánea cle una larguísima continuidad en la conducta de los asuntos políticos de los pueblos de la región andina.

Para resumir, las tres continuiclacles que, a mi entencler, constituyen factores de significación para la comprensión clel contexto histórico contemporáneo del Pacto Andino, son: el centralismo, la compleja tradición diplomática moclerna de nuestros países, y la gravitación centripeta de los pueblos que clurante siglos han habitado las regiones entre los Ancles y el mar. 
Es evidentemente clifícil $y$ se presta a controversia establecer la importancia relativa de las continuidades en la determinación de una situación contemporánea específica, pero infinitamente más complicado es el problema - - sin solución definitiva, descle luego- de escoger entre la multiplicicidad de cambios que caracterizan a nuestra época, aquellos que tienen influencia significativa sobre la vida politica de un grupo de países. Para ordenar mejor esta parte de la hipótesis de trabajo que intento presentar, trataré de proceder descle lo general hacia lo particular, empezando con aquellos cambios que afectan a la situación internacional en su totalidad para llegar a una consideración de aquellos que a mi entender modifican especialmente la situación política de los paises del Pacto Andino.

EL FIN DE IA GUERRA FRIA

Existe discrepancia respecto de fechas, pero evidentemente la Guerra Fría terminó durante la década de 1960. Se podría argumentar que el comienzo del fin lo marcó el conflicto Chino-Soviético, o que la conferencia de prensa del General De Gaulle, a principios de 1963, ofrece un buen hito para señalar la reordenación política de la coalición occidental. Cualesquiera la fecha, el hecho que creo conveniente destacar es que el fin de la Guerra Fría marcó también la terminación de un período clurante el cual la política exterior de los países de América Latina encontró limitaciones consiclerables para su proyección hacia el ámbito extralatinoamericano.

La modalidad intralatinoamericana de la politica exterior de nuestrơ países durante el siglo pasado y las primeras tres décadas del actual, no encontró desafíos importantes que la orientaran hacia una participación mayor en los asuntos mundiales. Este desafío eficiente. surgió por primera vez como consecuencia de la gran crisis cle 1929 que impresionó en los latinoamericanos el convencimiento de que nuestros países se encontraban en una posición eminentemente dependiente de factores y decisiones sobre los cuales no tenían ni conocimiento ni control efectivo a ningún nivel. La gran crisis que tuvo efectos devastadores sobre la economía de nuestros países, reforzó lo que movimientos políticos revolucionarios y nacionalistas habian estado predicando sin mucho éxito durante la década anterior. Una situación de desempleo masivo, paralización económica y gravisimo deterioro de los términos de intercambio, causaclos no por una admi- 
nistración ineficiente $\mathrm{O}$ corrupta, sino por fenómenos financieros ocu. rridos en otras latitudes y sobre los cuales ninguna ingerencia cabía a los gobiernos soberanos de nuestros países, no pudo sino reforzar considerablemente las posiciones nacionalistas. Durante la década de 1930, los principales gobiernos de América Latina, así como los más dinámicos partidos de base popular, empezaron a moverse hacia una reconsideración de las relaciones políticas y económicas de nuestros países con el resto del mundo. Creo razonable generalizar. acerca de esto y sugerir que la apreciación funcional de nuestra interclependencia con el ámbito extralatinoamericano se inicia definitivamente durante los años que siguieron a la gran crisis. Más aún, creo que fue durante esos años cruciales que por primera vez nuestras naciones iniciaron a varios niveles - clesde el académico hasta el político activo- la formulación cle políticas extralatinoameticanas, más o.menos coherentes y funcionalmente relacionadas con la apreciación de nuestra situación dependiente.

Esta tendencia se vio neutralizada con el estallido de la Segunda Guerra Mundial que, al dividir al mundo en dos grandes coaliciones, movió a nuestros países por razones de situación geográfica y convicción a alinearse con las naciones aliadas contra las potencias del Eje. En cierto sentido me parece lícito sugerir que la Segunda Guerra Mundial, cualesquiera el grado de participación de algunos en las acciones bélicas -Brasil y México; por ejemplo, tuvieron un papel más activo que los clemás- limitó considerablemente las posibilidades de que proyectáramos afuera de nuestra región, una politica exterior basada en la nueva apreciación de lo que constitufa el interés nacional: los alineamientos fueron casi automáticos $y^{\prime}$ no dejaron mucho margen para maniobrar.

El fin cle las hostilidades no resultó en una modificación substancial de la situación, puesto que apenas terminaclo el conflicto y cuando nuestras cancillerias se entregaban con entușiasmo a progxamar esquemas de cooperación el nivel de las Naciones Unidas, la enunciación de la Doctrina Truman -en 1947- nuevamente planteó una división del munclo que escapaba absolutamente del control de nuestros países y que al mismo tiempo nos alineaba de modo prácticamente inevitable. Dejando de lado las declaraciones formales de adhesión a la posición bccidental en la nueva confrontación mundial, creo que cabe preguntarse con cuánta sinceridad fue aceptado el dilema de la Guerra Fría en el ámbito político latinoamericano. Indudablemente resultó claro para muchos que tal aceptación abrị́a la puerta para la recepción de ayuda militar y económica cuantiosa, 
pero de ahí a establecer que los postulados de la Doctrina Truman fueron aceptados como propios por nuestros gobiernos, estimo que hay una distancia importante.

De todas maneras, el hecho concreto es que el desarrollo de politicas extralatinoamericanas sufrió una postergación inevitable. La actividad diplomática mundial se concentró en las maniobras de las dos grandes potencias por extender zonas de influencia, asegurarse una clientela leal y' obstaculizar los esfuerzos de la potencia rival en direcciones similares. Las tensiones cle la confrontación generaron temores reales que llevaron a muchos países a postergar temporalmente sus intereses y delegar responsabilidacl en organismos supranacionales sui generis. Así surgieron en pocos años, una serie de alianzas que confundiéndose con las esperanzas de cooperación mundial surgidas luego clel holocausto de la Segunda Guerra, dieron a muchos la impresión cle que el mundo daba por fin las espalclas al nacionalismo y avanzaba con pasos rápiclos hacia la instauración de un nuevo internacionalismo. Tales alianzas incluyeron el Pacto cle Bagdad, la oTAN, CENTO, sEaTo, ANzus, el Pacto de Varsovia, y, por supuesto, la nueva Organización de Estados Americanos que replanteó en sus origenes la idea de la colaboración interamericana como un subproducto de la Guerra Fría. Ascendió la marea de la Guerra cubriendo a su paso los picachos de los intereses nacionales de las naciones medianas y pequeñas que formaban la clientela de las dos Grandes Potencias: al descender, durante la última década, estos intereses han reaparecido vigorosamente, puesto que no habian siclo eliminados, sino que solamente postergaclos en función de regímenes supranacionales de cooperación defensiva u ofensiva frente a la amenaza o real de la potencia rival. Así es como el proceso de atenuación clel conflicto está marcado por el colapso - como en el caso del Pacto de Bagdad - o por la pérdida de la significación política y militar de estas alianzas, como es el caso de la OTAN, después de su expulsión de París por el Gobierno del General De Gaulle, o de la sEaTo, que ni siquiera está en condiciones reales cle conocer oficialmente la existencia cle un conflicto armado en Indochina, o de la ozA, cuya autoridad moral y política, amén de su eficiencia como organismo internacional, está siendo crecientemente cuestionada por las naciones de América Latina ${ }^{21}$.

atEs importante anotar que ni el colapso clel Pacto de Baghclad, ni la crisis que afecta a las otras organizacioncs supra-nacionales de la guerra fría han sido el resultado de acciones de la potencia rival, sino que la consecuencia del resurgimiento del nacionalismo, la proliferación policéntrica $y$ la restauración de la fluidez en la política internacional. 
Simultáneamente, la situación internacional se caracteriza por una vigorosa proliferación del policentrismo; no es posible ya pensar en un área socialista homogénea y controlada desde ésta o aquella capital; algo parecido ocurre en el campo occidental donde la hegemonía política estadounidense ha sufrido limitaciones de consideración hasta el punto que su posición en el mayúsculo conflicto de Indochina está prácticamente huérfana cle apoyo de parte de las principales naciones de Occidente. El policentrismo no es estático sino que ha surgido paralelamente con la restauración de un extraordinario grado de fluidez en los asuntos internacionales que abre, por primera vez desde la década de 1920, una oportunidad real a las naciones de América Latina de proyectar sus políticas exteriores hacia el ámbito extralatinoamericano.

PODER EGONOMICO, MILITAR Y POLITICO: ¿UNA CORRELAGION SUPERADA?

Desde que Maquiavelo lo definiera tan decidoramente en El Principe, más de cuatro siglos atrás, ha siclo casi axiomático en cuestiones politicas internacionales que aquella nación que no posee poder económico o militar significativo, no tiene mucho que hacer en el ámbito político exterior. Aparentemente, la novísima situación de fluidez $\mathrm{y}$ policentrismo que ha seguido al fin de la guerra fría sugiere que esta correlación clásica no tiene la aplicación que tuviera anteriormente. En primer lugar, el desarrollo de los armamentos termonucleares no ha entregado a sus poseedores un poder político comparable con su capacidad destructiva. Por el contrario, la misma envergadura de estos disuasivos ha tendido a inmorilizar a las grandes potencias frente a ciertos desafíos de tipo nacionalista. Las armas atómicas son tan inútiles para someter a las naciones medianas y pequeñas reacias a acatar las indicaciones de la potencia hegemónica, como podría ser una ametralladora para mantener orden dentro de un kindergarten. Las dos potenciạs hegemónicas aparecen como dos enormes entes, armados hasta los dientes, inmovilizados por el peso tremendo de sus armamentọ y abrazados en un esfuerzo sincero por no perturbar un orden estạblecido que precisamente incluy'e sus posiciones hegemónicas sobre una parte del globo. Cada una de ellas comprometida por razones de supervivencia y reciprocidad funcional a respetar la esfera de influencia del otro: así, Estados Unidos aparece imposibilitado de intervenir en Checoslovaquia y la Unión Soviética, en Santo Domingo. Ämbos mostrando una tremenda capacidad para resistir desafíos en su respectiva esfera de influencia siempre que éstos no reciban apoyo ima- 
ginario o real del contrincante mundial, pero al mismo tiempo, eminentemente vulnerables a los desafíos desde su propio campo, cuyos orígenes o tendencias son próximas y no pueden ser asociados con iniciativas o apoyo del rival hegemónico. De este modo, cualesquiera el disgusto del Gobierno de Estaclos Uniclos con el General De Gaulle; nunca se pudo acusar al líder francés de ser comunista o de estar bajo influencia indebicla clel ámbito socialista. Igualmente inconcebible es que la Unión Soviética pudiera acusar al Gobierno de Rumania de colusión con Estados Uniclos, o de pretender abandonar el campo socialista.

Esta nueva situación ha reforzado la fluidez evidente que se nota en el campo internacional y que permite que en la estructuración de su política exterior las naciones tengan pocas o ninguna dificultad en cruzar líneas ideológicas según convenga esto para adelantar lo que ellas consideran es el interés nacional. He ahí, por ejemplo, que uno de los más estrechos nexos funcionales con que cuenta Cuba en el exterior, aparte de los países de la órbita socialista, es con España, que ha servido en forma eficaz como puerta de entrada para los productos cubanos en el mercado de Europa; igual cosa rige a la inversa; puesto que España es un proveedor no despreciable de productos manufacturados - incluyendo naves de alta mar- para la creciente marina mercante cubana. Japón, Australia y Hong-Kong son los principales clientes de la República Popular China y son simultáneamente principalísimos inversionistas en Tairrán. La República Federal Alemana -que hasta hace muy poco mantenía una línea rígicla respecto de la Doctrina Hallstein, tiene un comercio de más de mil millones de dólares anuales con la República Democrática Alemana; la misma Re. pública Federal que vería con malos ojos que una nación del Occiden. te europeo o de América Latina estableciera relaciones diplomáticas formales con la República Democrática Alemana, comercia activamente con Hungría y Rumania, ambas naciones que mantienen excelentes vínculos diplonáticos con Alemania Democrática. Los ejemplos pueden multiplicarse ad infinitum; evidentemente existe actualmente una gran amplitud de maniobra que ha resquebrajado y pulverizado las barreras diplomáticas levantadas clurante los años peores de la Guerra Fría.

Bajo ciertas condiciones, cuya vigencia tiende a extenderse, los paises medianos y pequeños gozan actualmente de posibiliclades de maniobra cliplomática mucho mayores de lo que podría sugerir su poder económico o militar.

Esto puede plantearse también diciendo que la capacidad relativa 
de negociaciones de las naciones medianas y pequeñas ha aumentado mucho más que su poder económico y militar. Desde luego abunclan los ejemplos anteriores a la época actual en que naciones pequeñas han defendiclo exitosamente su independencia y han manteniclo posi. ciones externas clesagraclables para las grancles potencias, contanclo só. lo con un fuerte apoyo cloméstico y un grado envidiable de enterezal moral. Tal es el caso bien conocido de la República de Irlancla, por ejemplo, que durante la segunda guerra mundial mantuvo su neutralidad a pesar de las fuertes presiones de toda índole por parte cle Gran Bretaña y Estados Unidos. Incluso cuando se vislumbró la posi. bilidad de que las potencias decidieran utilizar las fuerzas para lograr su objetivo, el gobierno irlandés dejó bien en claro que su pequeño ejército $y$ todo el pueblo, defenderia con sus vidas su decisión cle mantenerse neutrales. Sin entrar en los aspectos positivos o negativos de la actitud irlandesa en esos momentos, es evidente que en ciertas situa: ciones una nación pequeña y relativamente débil, puede mantener: posiciones que contrarían los deseos de vecinos podexosos siempre ${ }^{\prime}$ cuando tales posiciones estén sólidamente basadas en un apoyo clomés. tico masivo y un liderazgo político claro y decidido22.

\section{VERTICALIDAD EN CRISIS}

El fin de la Guexra Fría, la superación relativa de la correlación clásica entre poder económico y militar y capacidad de maniobra diplomática, la crisis económica estructural que afecta a nuestros países $y^{\prime}$ el fracaso generalizado de los esquemas clesarrollistas adoptados con mayor o menor entusiasmo clurante las últimas dos décadas, han llevado a las naciones de América Latina a cuestionar la verticalidad que ha dominado sus relaciones exteriores políticas y' económicas.

No hace falta entrar a describir en detalle las causas de esta verticalidad, basta señalar que si bien clurante el centenar de años que procedieron a la clécada de 1930 la orientación fue primordialmente hacia Europa, desde entonces hasta ahora ha predominado obviamente la influencia - $y$ a veces la ingerencia- de Estados Unidos. Esta influencia no ha siclo siempre el resultado de los esfuèrzos estado-

=..."The Irish armed forces were very small; there was no question of successful resistance. But resistance there would have been, and the prospect of stirring up the Irish problem in all its complexity was more then either Britan or the United States could comfortably' face. The result was intense irritation but De Valera had his way in all essentials and Eire clinged to neutrality with religious zeal to the end of the war". David Vital, The Inequalily of Slates, Oxford, 1967, pp. 101-102. 
unidenses; no han faltado casos en que los latinoamericanos se han mostrado más que dispuestos a invitar el acrecentamiento de esta condición dependiente, y'a sea en nombre de intereses comunes reales e imaginados, de necesidades técnicas o financieras o inclusive como producto del convencimiento - también síntoma de una fuerte depenclencia cultural- de que Estados Uniclos representa una especie de Roma del mundo moderno y que la única alternativa viable para llevar adelante a nuestros países, es asociándonos con aquel centro de poder.

Esta verticalidad funcional se reflejó sobre una opinión 'pública que casi instintivamente, cacla vez que una iniciativa latinoamericana se apartaba de la rutina, dirigía sus ojos hacia Washington buscando en la reacción oficial cle aquel gobierno, o inclusive en los comentarios de prensa, una indicación sobre la calidad $y$ 'proyecciones de tal iniciativa.

Evidentemente, existe hoy día una disposición marcada en prácticamente todos los sectores del aspecto político y en la mayoría de los gobiernos de los países de América Latina, por modificar esta verticalidad. Esta se manifiesta, descle luego, en la actitud enfática del Goi bierno de Cuba, pero también en el espíritu y términos del Consenso. cle Viña del $M a r^{23}$ y en un clima político general que - por ejemplo-hace casi inconcebible hoy día que un candidato a posiciones de responsabiliclad pública pueda llevar adelante una campaña electoral exitosa con un programa abiertamente proestadounidense. Este cuestionamiento de la verticalidad no es, como muchos pudieran imaginar, una variación más sobre el rutinario tema clel antiyanquismo de la Guerra Fría. Por el contrario, su estilo y vertebración sicológica con positivos antes que negativos y no buscan necesariamente la confrontación sino que pretenden establecer las relaciones entre nuestros paises y la nación del norte sobre nuevas bases más acordes con una situación que ha cambiado mucho durante la última década.

Se diferencia además de fenómenos vagamente similares ocurridos anteriormente. - por ejemplo el cambio de la política exterior proeuropea de Brasil, bajo Río Branco, en favor de una política pro-

a'Basta recordar el p'́teámbuio clel Consènsö que lee, "Los países miembros de la CECLA afirman la personalidad propia de América Latina. El proceso de desarollo de la región y las transfomaciones que se están operando en cada uno de sus paises, uniclas a los cambios que ocurren en el mundo, imponen modificaciores importantes en. las modalidades de las relaciones de América Latina con los demás miembros de la comunidad internacional. Es ineludible, por lo tanto, que los países latinoamericanos procuren alcanzar soluciones claboradas con criterios propios, que -reflejen su iclenticlad nacional". 
estadounidense - en que no trata de liberarse de un tipo de dependencia para caer en otra, sino que está firmemente enraizada en una convicción nacionalista que dirige la atención no hacia nuevos modelos extralatinoamericanos, sino que pretende por primera vez definir: una arquitectura politica propia. Los alcances de esta nueva orienta* ción son difíciles de predecir, pero es indudable que afectan de un modo más profundo y general a todo el ámbito en el que se desenvuelven las actividades de estado que cualquier fenómeno similar anterior en nuestra historia contemporánea.

Uno de los aspectos principales de esta crisis de la verticalidad, se refiere a la aspiración - a veces no bien definida, pero claramente presente- de enriquecer y aumentar las opciones abiertas a nuestra política exterior.

Ya no satisface el establecer relaciones con los países socialistas exclusivamente como un gesto simbólico de desafio a la potencia hegemónica, sino que se busca la estructuración de esquemas funcionales de colaboración económica. Igualmente, a la retórica del Tercer Mundo, ha sucedido el deseo de programar una coordinación efectiva con algunos de los paises, por ejemplo en Africa - con los cuales evidentemente existen nexos de interés bien concretos. Quizás la mejor ilustración de esta tendencia sea la Conferencia de Lusaka y la crea. ción de crPec, aunando los esfuerzos de Zambia, el Congo, Perú y' Chile para racionalizar la comercialización del cobre en los mercados mundiales.

Igualmente promisorio es el interés latinoamericano por abrirse hacia el Pacífico, del cual esta conferencia es una manifestación elo: cuente y de cuya validez las deliberaciones de los últimos días son la mejor evidencia.

Aparte de muchas otras consecuencias sobradamente conocidas, la firma del Acuerdo de Cartagena ha dividido a la América del Sur en tres: Brasil, Argentina y' las naciones del Pacto Andino. Esta división, aus. piciosa para el diálogo constructivo', pone fin a la larga tradición de diplomacia intralatinoamericana, basada sobre conceptos clásicos del equilibrio de pocler. De tener éxito la iniciativa - como seguramente lo tendrá - nuestra parte del mundo gravitará alrededor de tres centros de influencia, cuy'as relaciones entre si posiblemente derivarán hacia modalidades que se apartan de lo que hasta ahora hemos cono. cido. Desde luego, el resurgimiento nacionalista universal afecta a es- 
tos tres centros, de manera diferente. Para nadie es un secreto que la firma del Pacto Andino fue recibida sin mucho entusiasmo por las cancillerías de Brasil y Argentina, pero es también evidente que a esa primera frialdad ha sucedido una actitud abierta - que encuentra un eco vigoroso en las naciones signatarias - a encontrar modos efectivos de aunar esfuerzos por adelantar los intereses comunes de la región.

Pero la clefinición de interés nacional y la adopción cle medidas para favorecerlo, clifieren marcadamente. Mientras en Brasil y Argentina predomina una actitud más bien excéptica respecto a las iniciativas integracionistas, en el ámbito andino se estima que, por el con. trario, es a través cle una integración vigorosamente nacionalista, con raices y estilo propios, que se encuentran las mejores posibilidades de neutralizar $y^{\prime}$ supperar la conclición dependiente de nuestras nacionẹs. Más aún, las naciones del Pacto Andino no están tratando de buscar un régimen de integración supranacional, que haga necesaria la delegación o postergación de soberanía o intereses nacionales en aras de una supuesta eficiencia. No existe, en este caso - como ocurrió durante las primeras etapas de la formación del Mercado Común Eu. ropeo- una ideología integracionista que se base en la atenuación de lo nacional. Muy por el contrario, se busca la creación de esquemas originales de integración que coordinen los intereses nacionales sin limitar o postergar de ningún modo la soberanía de los paises participantes.

Representa esta situación un cambio sustancial cle lo que conociamos hasta hace pocos años. El carácter integracionista del Pacto Andino es enfáticamente latinoamericano $y^{\prime}$ no un subproducto de la Guerra Fría. Su formación ha generaclo cambios en la ordenación tradicional de los sistemas de equilibrio que acentuaran la importancia de la diplomacia intralatinoamericana clurante el futuro próximo. Finalmente, el nacionalismo de los paises signatarios es precisamente un elemento dinámico en este proceso sui generis de integración, diferenciándose por esto del nacionalismo igualmente legítimo de otros países sudamericanos.

\section{EL PACTO ANDINO EN EL CONTEXTO DE LA HISTORIA CONTEMTPORANEA}

Toda reflexión histórica es selectiva. Sabemos demasiado y lo que sabemos es a la vez demasiado vago para poder creer que se pueda llegar a escribir una historia definitiva, absolutamente objetiva $y$ basada en hechos cuya definición no admite variaciones. Hubo una sola Revolución Francesa, pero su significado y proyecciones continuarán 
siendo apreciados e interpretados descle puntos cle vista cambiantes mientras haya seres humanos que se preocupen de estudiarla. Desde este punto de vista - que como toda reflexión listórica admite discusión - cada generación exige e inevitablemente consigue, su propia historià.

Estas consideraciones rigen para el pasado lejano, pero igualmente tienen aplicación cuando se examina una situación contemporánea. Existe en este último caso además una tentación irresistible de deslizarse hacia la profecía que quizás conviniera que fuera resistida con más frecuencia, pero que es innegable que juega un papel importante en la determinación cle los criterios que modifican una visión histórica de lo contemporáneo.

Todio esto lo tengo muy' presente al proponer que los siete factoyes que he descrito muy brevemente en este ensayo preliminar, sugieren una interpretación optimista del significado del Pacto Andino en èl contexto histórico contemporáneo. Me atrevería a proponer con cierta-vacilación difícil cle evitar, que el Pacto Andino está en una situación de oportuniclad sin paralelo en el mundo contemporáneo tanto por las continuiclades que lo vertebran, como por la naturaleza de los cambios domésticos $y$ ' externos que lo modifican. Los cuatro cambios que he mencionado cleterminan a su vez circunstancias especiales que, vistas desde América Latina en general y descle las naciones del Pacto Andino en particular, podrian ser clescritas del siguiente modo: primeramente, el fin de la Guerra Fría -abundantemente comentado e interpretado - ha devuel to la fluiclez a los asuntos internacionales y ha ampliado la posibilidad de maniobra cle las naciones medianas y pequeñas en el plano externo. Evidentemente, ninguno de estos dos fenómenos tiene un carácter absoluto y su aprovechamiento depende de otros factores, pero lo importante es que las rigideces impuestas por la confrontación entre Estados Unidos y la Unión Soviética han sido superadas de modo apreciable.

Al fin de la Guerra Fria en el ámbito mundial se suma la terminación - dentro de América del Sur- de un esquema cle equilibrios de poder tradicional basado en la división y la rivalidad interna de las naciones 'de la costa del Pacífico. Este esquema está siendo superado $y^{\prime}$ reemplazado por otro que en forma muy preliminar podría ser descrito como de tres áreas de influencia: el Brasil, Argentina $y$ las naciones del ipacto Andino.

En tercer lugar, se percibe en el campo internacional, una atenuación marrcacla cle la clásica correlación entre el poder económico, el poder militax $y$ la capacidad para llevar adelante una polftica exterior 
independiente y positiva. Esta atenuación se traduce, evidentemente en oportunidades para aquellas naciones medianas $y$ pequeñas que tengan un grado satisfactorio cle viabiliclacl y que estén dispuestas a aprovecharlas. En el caso cle América Latina, me atrero a sugerir que el deseo de aprovechar la oportuniclad ya está presente. Los planteamientos hechos por la CECLA ofrecen alguna eviclencia positiva que la clisposición de algunos gobiernos andinos de reconsiderar actitudes asumiclas anteriormente respecto clel régimen cubano también indica un .cambio de dirección interesante. En vista de éstos y otros factores clecidores, creo razonable sugerir que existe actualmente en nuestra América el cleseo de alejarse de la verticalidad que ha caracterizado a nuestras relaciones exteriores clurante tanto tiempo.

Estos cuatro factores, tres de ellos cle carácter pasivo $y$ uno dinámico, reflejan situaciones complejas: por ejemplo, el deseo de poner fin a la verticalidad en nuestras relaciones externas se encuentra estrechamente relacionado con nuestra apreciación del proceso de dependencia $y$ todas sus implicaciones, como asimismo, con los cambios sustanciales que se están llevando adelante en varias de nuestras naciones respecto de los esquemas participatorios y redistributivos. Lo importante, sin emloargo, es que los cuatro factores de cambio, tomados conjuntamente, determinan un desafío ante el cual las naciones del Pacto Andino se encuentran en condiciones notablemente más favorables que las que existen en cualquier otro grupo comparable en el mundo contemporáneo.

Primeramente, estos cambios exigen de las naciones que buscan aprovechar la fluidez coyuntural, una capacidad réalmente dinámica para operar en el plano doméstico con rapidez y flexibiliclacl, representando directamente a los sectores principales de la economía nacional y, por supuesto, a los intereses nacionales en su conjunto. Al mismo tiempo, es necesario que estas clecisiones políticas puedan proyectarse hacia el ámbito exterior en forma sistemática y' práctica.

Los países clel Pacto Anclino tienen en su conformación políticoeconómica dos factores cle continuiclacl que, cualesquiera su carácter en el pasado reciente, se transforman hoy día en claras ventajas para llevar adelante este tipo de política: éstos son el robusto centralismo cle nuestras estructuras políticas y la compleja y eficiente tradición diplomáticar calracterística de nuestros ciento cincuenta años de vida republicana.

Luego, es igualmente claro que para poder operar con alguna posibilidad de éxito en el concierto internacional, se necesita una base cle apoyo más amplia y cleciclor que aquelia ofrecida por los marcos 
ESTUDIOS INTERNACIONALES

nacionales tradicionales. Esta base se ha buscado en otras oportunidades en esquemas cle integración supranacionales o proyectos continentales, que ya sea por su excesivo eclecticismo o por chocar contra el nacionalismo resurgente, no pueden alcanzar los resultados esperados. En el caso de los países del Grupo Andino, la tradición centrípeta del área entre los Andes y el mar, señalada en cuatro instancias históricas de consideración, sugiere que la posibilidad de estructurar una coordinación viable entre estas cinco naciones encontrará menos obstáculos de los que inhiben a iniciativas similares en otras partes del mundo. 